\title{
O Processo de Decisão da Mãe Sobre a Cirurgia Cardíaca para o Filho
}

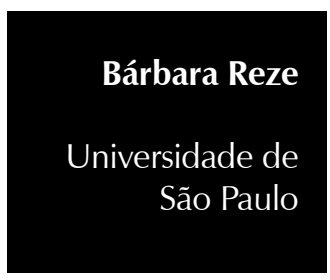

http://dx.doi.org/10.1590/1982-3703000072012
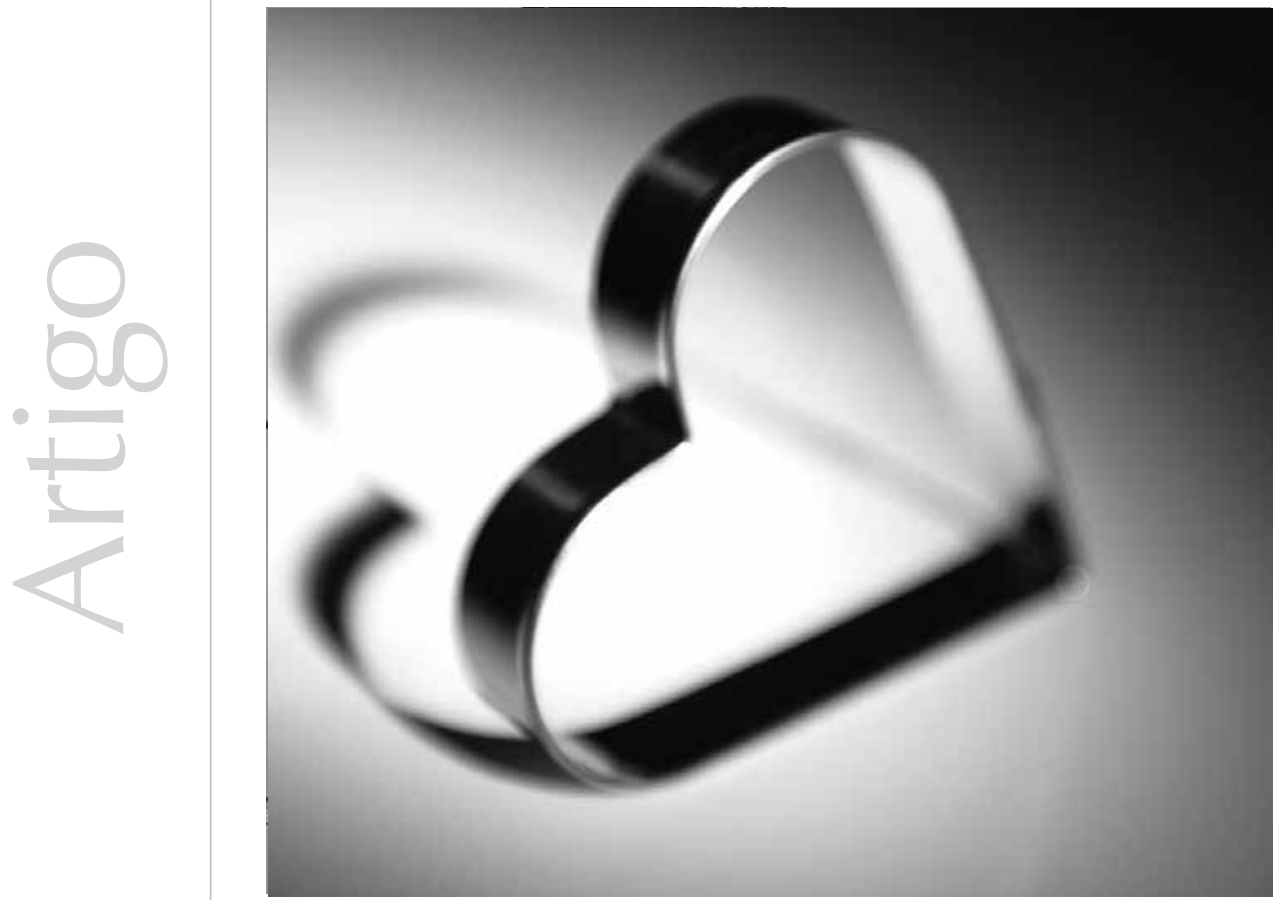
Resumo: Esta pesquisa investigou atitudes maternas na decisão da cirurgia cardíaca paliativa para o filho. Com referencial da pesquisa clínico-qualitativa, entrevistou-se duas mães de crianças cardíacas submetidas à cirurgia paliativa. Observou-se atitudes de hesitação, questionamento, recusa da realização da cirurgia e atitudes de não pensar e aceitação imediata do procedimento. A partir da psicanálise, analisou-se a recusa da realização da cirurgia como recusa-reflexão: esta não seria uma defesa psíquica ou uma reação precipitada da mãe, mas uma atitude possível, nem sempre definitiva e que auxiliaria na assimilação dos acontecimentos, às vezes traumáticos, relativos à decisão. Entendeu-se a decisão como um processo, sendo um momento oportuno de reflexão para que a mãe e a família tomem uma decisão ponderada e consequente.

Palavras-chave: Tomada de decisão. Relações mãe-criança. Atitudes frente à doença. Relação médicopaciente.

Abstract: This research investigated maternal attitudes in palliative cardiac surgery decision making for their children. In reference with clinical-qualitative studies, two mothers of children undergoing palliative cardiac surgery were interviewed. We observed the attitudes, hesitation, questioning, refusal of the surgery, and attitudes of not thinking and accepting immediately the procedure. Based on psychoanalysis, refusing the surgery was analyzed as reflections of denial: this would not be a psychic defense or a hasty reaction by the mother, but a possible attitude, not always definitive and that helps with the assimilation of events, sometimes traumatic for decision-making. We understood the decision as a process, being an opportune moment for reflection so that the mother and family make a pondered and reasonable decision.

Keywords: Decision-Making. Mother-child relationships. Attitudes when facing disease. Doctor-patient relationship.

Resumen: Esta investigación ha observado actitudes maternas en la decisión de la cirugía cardíaca paliativa para el hijo. Con referencial de la investigación clínico-cualitativa, se han entrevistado a dos madres de niños cardíacos sometidos a la cirugía paliativa. Se han observado actitudes de dudas, cuestionamiento, rechazo a la realización de la cirugía y actitudes de no pensar y aceptación inmediata del procedimiento. A partir del psicoanálisis, se ha analizado el rechazo de la realización de la cirugía como rechazo-reflexión: ésta no sería una defensa psíquica o una reacción precipitada de la madre, sino una actitud posible, ni siempre definitiva y que auxiliaría en la asimilación de los acontecimientos, a veces traumáticos, relativos a la decisión. Se ha entendido a la decisión como un proceso, como un momento oportuno de reflexión para que la madre y la familia tomen una decisión ponderada y consecuente.

Palabras clave: Toma de decisión. Relaciones madre-niño. Actitudes ante la enfermedad. Relación médicopaciente.

A indicação de cirurgia cardíaca para o filho é uma situação crítica para os pais, pois, ao envolver risco de morte, pode fazer com que vivam um processo crucial de decisão. Ao analisar estudos sobre o tema, constata-se que a doença orgânica crônica do filho nem sempre conduz os pais a uma aceitação plena das indicações médicas, podendo haver a recusa, parcial ou total, da realização destas (GiannottiHallage, 1983; 1988; Higgins \& Kayser-Jones, 1996; Pinnock \& Crosthwaite, 2005; Vandvik \& Forde, 2000). A não aceitação tem, porém, implicações médicas, psicológicas, éticas e jurídicas distintas dependendo do tipo de intervenção, das consequências para a vida futura, da gravidade do quadro clínico, dos riscos. Delicada situação se instala quando os pais manifestam a não aceitação de uma intervenção cirúrgica para o filho menor de idade.
Distinguem-se três tipos de situações de recusa de tratamento: com consequências moderadas, graves (na fase curativa ou paliativa de uma doença grave ou cuja progressão conduz à morte) ou mortais (Hottois \& Parizeau, 1993). Este estudo focou a recusa de tratamento com consequências graves da cirurgia cardíaca paliativa para doenças cardíacas complexas. As cirurgias paliativas não trazem a cura do defeito cardíaco, sendo a correção anatômica difícil, com lesões residuais e evolução pós-cirúrgica desfavorável a longo prazo, requerendo acompanhamento clínico periódico ou cirurgias posteriores. Esse aspecto não definitivo dessa intervenção pode trazer insegurança aos pais na decisão. Mas se, por um lado, a cirurgia paliativa não elimina o risco de vida da criança devido ao prognóstico incerto, por outro lado, sua não realização 
significa a evolução natural de uma doença que, por sua vez, também representa risco de vida.

Há algumas décadas, não se dispunha dos atuais avanços científicos e tecnológicos da medicina, que utiliza variados recursos para diagnósticos, exames, cirurgias, reabilitação e cuidado intensivo de doenças crônicas infantis. Um diagnóstico que no passado representava uma sentença de morte para a criança, hoje, pode ser enfrentado se não com um tratamento e um prognóstico precisos, pelo menos com a perspectiva de alguma ação terapêutica até mesmo em casos graves e complexos. Preservar a saúde e a vida é o que estimula esses avanços, sendo sua importância indiscutível. Mas não se pode ignorar que, ao proporcionarem benefícios e minimizarem riscos para o corpo biológico, os recursos médicos repercutem também na vida subjetiva e nas atitudes frente à doença, ao tratamento, à cura e à morte.

Atualmente, reconhece-se cada vez mais a importância da participação do paciente e seus cuidadores no tratamento, em uma tendência de legitimar o ponto de vista de quem recebe as práticas médicas (Cohen \& Marcolino, 2002; Culver, 2002; Hossne, 2002; Kipper, Clotet \& Loch, 2004). Apesar de muitas vezes as reações subjetivas a essas práticas serem dadas por óbvias, nem sempre elas correspondem ao que é esperado socialmente - como nos casos de não aceitação de uma recomendação médica. Neste estudo, propôs-se problematizar as reações subjetivas diante de uma prática médica buscando nuanças da experiência da mãe, como a dúvida e a hesitação, para que sejam postas em evidência em tempos de respostas e decisões rápidas. Por exemplo, como entender que com os avanços científicos na área médica, uma mãe possa considerar não aceitar a cirurgia cardíaca para o filho enquanto alternativa para minimizar os danos da doença, cuja evolução já se sabe potencialmente fatal? Questão sem dúvida complexa, que reforça a importância da consideração dos vários fatores e perspectivas subjetivas envolvidos em uma decisão de tal porte como a relativa a uma cirurgia.

Sendo assim, este estudo investigou as atitudes maternas na decisão da cirurgia cardíaca para o filho e discutiu a recusa da realização desta. Esses objetivos foram buscados a partir da pesquisa em campo e de elementos teóricos da psicanálise, a partir de Freud. O uso do termo "atitudes maternas" visa enfatizar a conotação de tendência do que é manifestado no processo decisório: entende-se a atitude como uma orientação para a ação, mas ainda não a ação realizada. Os termos "atitude de aceitação" e "atitude de recusa" se referem à tendência da mãe de aceitar ou não a cirurgia e não a aceitação ou a recusa já consolidadas.

\section{Método}

Utilizou-se a abordagem da pesquisa clínico-qualitativa (Turato, 2008) para buscar elementos da experiência materna na decisão sobre a cirurgia do filho. O campo da pesquisa para a coleta dos dados foi a Associação de Assistência à Criança Cardíaca e à Transplantada do Coração (ACTC). Trata-se de instituição filantrópica que presta assistência a crianças/adolescentes cardiopatas em tratamento médico no Instituto do Coração (Incor) do Hospital das Clínicas da Faculdade de Medicina da Universidade de São Paulo. É um serviço de apoio extra-hospitalar que oferece hospedagem, alimentação, transporte, apoio social, psicológico e pedagógico para a criança/adolescente e sua mãe/ acompanhante.

Foram duas as participantes que corresponderam aos critérios estabelecidos dentro do prazo da pesquisa: ser mãe de criança de até onze anos de idade com diagnóstico de cardiopatia complexa, que 
tenha recebido indicação passada de cirurgia paliativa e já a tenha realizado. $\mathrm{O}$ instrumento foi a entrevista semidirigida individual, com questões objetivas sobre a mãe, o diagnóstico da criança e a composição familiar e a seguinte questão disparadora: "Como foi para você receber a indicação cirúrgica para seu filho?". Na análise das entrevistas, foram utilizadas as técnicas de leitura flutuante e categorização (Turato, 2008). Foram feitas, também, considerações sobre o campo da pesquisa, tendo como base informações obtidas do site da associação (Actc, 2010) e observações oriundas das visitas atuais para as entrevistas e da experiência passada da pesquisadora como psicóloga nessa instituição.

\section{Resultados e Discussão}

\section{Apresentação dos Casos}

No caso 1, a participante tinha uma filha de dez anos, diagnosticada com cardiopatia em seu primeiro dia de vida. Foi encaminhada para tratamento em São Paulo, onde soube que a cirurgia, que já havia sido indicada no momento do diagnóstico, se daria em três etapas. No caso 2, a participante tinha uma filha de sete anos diagnosticada com cardiopatia aos quatro meses de vida. Foi encaminhada para tratamento em São Paulo, onde recebeu a indicação cirúrgica, que se daria em três etapas.

\section{Análise das Entrevistas}

A análise das entrevistas teve como referência a teoria psicanalítica, a partir de Freud. Estabeleceram-se as seguintes categorias temáticas comuns às duas entrevistas: a) Reações ao diagnóstico; b) Reações à indicação cirúrgica; c) Ambivalências; d) A tomada de decisão e d.1.) O futuro (categoria relativa a apenas um dos relatos); e) Relação com o médico e a medicina; f) Relação com a filha.

\section{a) Reações ao diagnóstico}

No caso 1, a reação imediata da mãe ao relatar o recebimento do diagnóstico foi de interrupção da fala, silêncio e choro. Essa reação sem palavras evidenciou o impacto psíquico traumático do diagnóstico para a mãe, do qual decorreu um predomínio do impulso a agir em detrimento do pensar. Em geral, o recebimento do diagnóstico de cardiopatia introduz um risco de vida à criança, como se uma sentença de morte estivesse a ela atrelada. Por provocar uma surpresa, um choque, ocasiona intensas reações de angústia e pode ter consequências traumáticas (Knobloch, 2002).

É próprio do traumático o fator de surpresa e de perigo do acontecimento (Freud, 1920/1996), que provoca um incremento abrupto de tensão no psiquismo para o qual a pessoa não estava preparada. O excesso de excitação no psiquismo, quando não é assimilado nem descarregado, cria uma situação insuportável que seria, por isso, traumática.

Na situação traumática, os acometimentos repentinos permanecem como excesso de excitação e não entram no circuito de representações psíquicas, originando a angústia. Knobloch (1998) explica que o traumático não é organizado pelo sistema de representação nem, portanto, pela linguagem. As representações constituem o psiquismo, o inconsciente, e possibilitam a significação, a atribuição de sentido ao que é vivido. No instante do diagnóstico, aquilo que é experimentado como excesso de excitação é o afeto que não se liga a representação alguma; e não sendo possível designá-lo por meio de palavras, acontece apenas o silêncio (Knobloch, 2002). Silêncio que pôde ser observado na reação sem palavras no caso 1 quando, ao relatar o recebimento do diagnóstico, a participante interrompe a fala, fica em silêncio e chora. O afeto sem 
Quando uma experiência, como o diagnóstico para essa mãe, não ganha sentido nem vira palavra pelas vias da representação - pois não se inscreveu no circuito psíquico em que seria ligado a outras representações - o pensar fica em suspenso. ligação a representações produz angústia. A angústia pode ser expressão de uma dor sem representação decorrente do trauma, dor pela proximidade da morte, como explica Knobloch (1998). É uma dor sem palavras para denominá-la, que será afastada do psiquismo por uma reação de descarga. No caso 1 , o choro foi a reação de descarga, a angústia que transbordou, como se a dor sentida só pudesse ser expressada pelo agir, só pudesse ser agida.

Além do impacto psíquico pela notícia em si, os acontecimentos concomitantes ao recebimento do diagnóstico desorganizaram ainda mais a vida da mãe: à crise normal do nascimento se somou a crise do diagnóstico de cardiopatia; o diagnóstico trouxe ameaças de separação e morte, e a perda da filha idealizada; o bebê ficou submetido a procedimentos e manipulações que interferiram nos primeiros contatos mãe-bebê; o deslocamento da cidade de origem a separou da família, do filho mais velho ainda pequeno, de sua casa e a introduziu em um ambiente desconhecido. Por serem consecutivos ao diagnóstico, esses acontecimentos penosos potencializaram seus efeitos traumáticos, trazendo a vivência de um morrer da vida tal como estava estabelecida até então. Tudo ficou em suspenso em uma indefinição quanto aos desfechos futuros para a vida da filha e a própria também.

Quando uma experiência, como o diagnóstico para essa mãe, não ganha sentido nem vira palavra pelas vias da representação - pois não se inscreveu no circuito psíquico em que seria ligado a outras representações - o pensar fica em suspenso. Prevalece, assim, o impulso para o ato como meio do psiquismo descarregar o excesso de excitações que traz dor e desprazer, ficando impossibilitado o trabalho de pensamento. No agir se reproduz uma agonia que foi sentida, mas que permanece incompreensível (Knobloch,
1998). O "não pensar" foi expresso pela mãe do caso 1 quando ela diz ter sido tudo muito rápido no diagnóstico: ela fez imediatamente a viagem para o tratamento fora do domicílio de origem sem que soubesse bem o que a filha tinha. É natural que nas situações de doença grave ocorra esse agir precipitado em função da urgência real de decisões e ações diante do frágil estado de saúde da criança. Mas, nesse caso, a velocidade dos acontecimentos externos se somou à dos acontecimentos internos: o momento do diagnóstico aglutinou tantas informações, mudanças, separações, preocupações e decisões em um curto espaço de tempo, que resultaram em uma espécie de vertigem em que não era possível à mãe, pensar.

A mãe do caso 2 apresentou uma reação diferente ao falar do diagnóstico da filha na entrevista: não se referiu imediatamente ao recebimento da notícia e quando o fez, foi de uma forma mais tranquila e sem manifestações emocionais agudas. Isso fez supor uma maior possibilidade materna de elaboração psíquica do diagnóstico, que não teve um impacto traumático para a mãe em razão de experiências familiares anteriores. O diagnóstico da filha colocou a mãe em um lugar materno semelhante ao de sua própria mãe, que também teve uma filha doente; reconvocou-a, assim, a um vínculo e a um cuidado atravessados pela doença e que lhe eram conhecidos - pela experiência da mãe e por sua experiência de cuidar da irmã - e, portanto, já tinham alguma representação psíquica. Essa familiaridade com o vincular-se, o cuidar e o ser mãe de alguém doente possibilitou a elaboração psíquica do diagnóstico. Se o aspecto inédito e de surpresa de uma experiência difícil pode torná-la traumática, no caso 2, a familiaridade com uma situação de doença foi entendida como um preparo psíquico, tendo uma função de angústia sinal (Freud, 1926/1996): forneceu representações e significações prévias que protegeram o psiquismo do 
aspecto inédito da experiência e ajudaram a suportar suas ameaças, pois remeteram a uma história e a uma memória familiar.

Cabe considerar que esta mãe recebeu o diagnóstico quando a filha já estava com quatro meses, enquanto no caso 1 o diagnóstico foi recebido pela mãe no primeiro dia de vida da criança. Esse tempo pode ter influenciado a forma distinta como ambas reagiram ao diagnóstico, dando à mãe do caso 2 um intervalo maior para passar pela crise normal do nascimento e estabelecer o vínculo mãe-bebê; um tempo para se reorganizar minimamente sem que mais uma nova condição (a da doença) se acrescentasse subitamente.

\section{b) Reações à indicação cirúrgica}

No caso 1, a primeira referência médica à necessidade de cirurgia foi concomitante ao diagnóstico de cardiopatia da filha. As reações dessa mãe à indicação cirúrgica foram de não pensar e de agir precipitadamente, observadas tanto na ida imediata para o tratamento em outra cidade quanto nas atitudes de aceitação da realização da cirurgia. A cirurgia foi referida como procedimento inquestionável e aceita imediatamente, sem mediação do pensamento. Não houve menção a hesitações, dúvidas ou a ponderação dos riscos, como se estes não pudessem ser pensados. A indicação cirúrgica pode fazer com que os pais vivam um processo crucial de decisão: são muitos os fatores que pesam, como o quadro clínico da criança, as estimativas médicas de vida, os riscos e prognósticos, as opiniões dos familiares e, principalmente, as expectativas do próprio paciente (Romano, 2001).

A esses fatores se soma a condição emocional diante de tal indicação médica: é frequente que o recebimento de uma notícia grave como a da necessidade de uma cirurgia, ocasione um torpor psíquico que prejudica a assimilação emocional do que está sendo vivido e, consequentemente, prejudica a capacidade de pensamento e de decisão. Analisou-se como houve, no caso 1, frente à confirmação da indicação cirúrgica, uma reedição da dinâmica psíquica da reação ao diagnóstico em que, em uma situação inédita e de angústia, o agir predominou sobre o pensamento. Isso fez supor um processo de decisão em que a aceitação da indicação médica, tanto a de realizar o tratamento em outra cidade quanto a recomendação de cirurgia, ocorreu sem reflexão.

Mas a tendência a não pensar e a agir foi entendida nesse caso não só como descarga da angústia, mas também como uma reação de resolução rápida do assunto para se proteger da irrupção da angústia. Como se o medo da morte funcionasse como uma impulsão, um motor que faz reagir, que faz viver (Brun, 1996). A velocidade do agir sem pensar daria a impressão de que se poderia passar mais rápido pela situação, como se assim não fosse sofrer.

No caso 2, nas reações à indicação cirúrgica predominaram atitudes de hesitação e recusa da realização da cirurgia. Estas estiveram perto de serem concretizadas, como mostra a afirmação da mãe de "pensar em tirar a filha do hospital", apesar da posterior aceitação da cirurgia. Associada ao medo da perda e ao prognóstico ruim, a recusa se manifestou quando a cirurgia significava perda e os riscos percebidos se sobrepunham aos benefícios.

É inevitável a ansiedade ao se pesar tudo o que envolve um ato cirúrgico: a anestesia, a viabilidade da correção do problema, a surpresa por complicações não detectadas antes, o risco de intercorrências, infecções ou sequelas, a recuperação pós-operatória. Além da preocupação com o êxito do procedimento em si, a cirurgia significa um período de nenhum ou pouco contato direto com o filho. Em geral, vista como último recurso, 
o clima emocional da cirurgia é crítico e se acirra pela carga simbólica do coração como órgão mitificado do instinto de vida e do amor (Romano, 2001). No caso 2, não submeter a filha ao procedimento pareceu uma reação imediata da mãe para proteger de tudo isso que envolve o ato cirúrgico.

Mas um outro sentido também foi apreendido dessa atitude da mãe: "pensar em tirar do hospital" demonstrou alguma abertura para o pensamento, para cogitar outras saídas em vez de acatar imediatamente a solução médica, apresentada como a única saída naquele momento. Tanto que a mãe não agiu isso, só pensou isso. O pensar, segundo Freud (1911/1996), é um processo que coloca em vinculação, em relação, elementos mentais como as idéias e as representações verbais. Isso possibilita ao psiquismo suportar maiores quantidades de excitação, pois, quando um elemento mental é ligado a outro, adia-se a sua descarga pela ação. Dessa forma, no caso 2 , a recusa que em um primeiro momento foi uma reação-ato de descarga, de não pensar frente à angústia (fazendo com que a mãe pegasse o elevador com a filha para tirá-la do hospital), pôde se transformar no momento seguinte em recusa-pensamento (a mãe mudou de ideia e não saiu do hospital nem abandonou o tratamento). A exposição das próprias intenções de recusar a realização da cirurgia a outras pessoas teve para esta mãe uma importante função de mediação entre o impulso a agir e a reflexão. A interlocução com os outros evitou decisões e ações impensadas, pois permitiu resgatar aspectos positivos e benefícios do procedimento, revertendo-se a recusa. Portanto, no caso 2 , as decisões foram mais refletidas e se beneficiaram da dúvida.

\section{c) Ambivalências}

Para a mãe do caso 1, as ambivalências da vida psíquica não eram suportadas pois traziam angústia. A perspectiva unilateral das experiências predominava: a cirurgia só era considerada em sua possibilidade de melhora, somente os afetos positivos, como confiança e pensamento positivo, eram manifestados e a atitude frente à cirurgia era de aceitação inquestionável de sua realização, sem que houvesse reconhecimento nem ponderação dos riscos e benefícios. Para Freud (1915/1996a), as ambivalências são intrínsecas à vida psíquica e ele chama de ambivalência de sentimentos a oscilação entre o amor e o ódio que pode existir nas relações objetais. Para explicar essa ambivalência, Freud remonta às relações iniciais do ego com os objetos/mundo externo e mostra como está associada ao prazer-desprazer (outra polaridade constitutiva da vida psíquica): o objeto que é fonte de prazer e de sensações agradáveis atrai o ego, que dele se aproxima amando-o e tomando-o para si (introjetando) ou fazendo-o uma parte de si (incorporando); o objeto que produz sensações desagradáveis e desprazer repele o ego, que dele se distancia odiando-o.

Apegar-se unicamente aos aspectos positivos, como a mãe do caso 1, é uma forma do ego afastar de si a percepção consciente dos aspectos dolorosos e negativos das experiências. Mas a evitação dos aspectos negativos fez com que estes se manifestassem no significado latente do discurso materno. Foram inferidas atitudes implícitas de recusar a cirurgia por meio da mitigação de sentimentos hostis, da projeção de aspectos depressivos e pessimistas e da atribuição ao futuro de um possível não aceitar.

Quando abordou a ambivalência de sentimentos nas atitudes diante da morte, Freud (1915/1996b) disse que a morte ou o risco de morte de pessoas amadas faz entrar em conflito no inconsciente duas atitudes opostas para com a morte: a de reconhecer a morte como extinção da vida, ou seja, real ameaça ao ser amado e a de negá-la, como se fosse uma ameaça irreal, como uma ideia 
A convicção de decidir pela cirurgia como uma decisão pela vida revela que, nesse caso, houve pouco espaço psíquico para a apreciação dos vários aspectos (risco e benefício, vida e morte) presentes em qualquer decisão. que não é concebida pelo psiquismo. Da ambivalência frente à morte, Freud demonstra como também há no inconsciente desejos de morte que podem se dirigir até mesmo às pessoas mais amadas. Ao evidenciar os desejos de morte inconscientes, Freud mostra que o inconsciente é dividido, ambivalente, o que pressupõe que tendências opostas de sentimentos, atitudes e ações possam coexistir e se manifestar simultaneamente.

No caso 2, os movimentos de ambivalência psíquica tendiam para a perspectiva negativa das experiências: medo de fazer a cirurgia, pensamentos de perda e morte da filha e percepção de riscos maior que a de benefícios. A cirurgia acirrou angústias de morte e foi sentida como uma ameaça maior de perda ou de prejuízo na vida do que aquelas oriundas do não tratamento. Essa tendência para o negativo foi uma das causas da atitude de recusa da cirurgia neste caso.

O mote do relato desta mãe era o viver sob o impacto da possibilidade da perda da filha, em um estado de alerta pela iminência da morte que cada procedimento médico (exame, cirurgia) atualizava. Pensou-se se esse sentimento permanente de vir a perder a filha, em parte, não independia da gravidade do quadro e dos tratamentos disponíveis, referindo-se àquilo que Brun (1996) descreve como a imagem psíquica da criança dada por morta. A persistência dessa imagem na vida psíquica da mãe fez com que ela ficasse sob o impacto de representações psíquicas do filho dado por morto e assim não pudesse acreditar, confiar, em possíveis melhoras. De fato, nesse caso, foi do outro que veio o resgate dos signos positivos e de uma visão otimista e menos assustadora da cirurgia. Apesar dos momentos em que não podia vislumbrar perspectivas futuras nem ter esperança, a decisão final de aceitação da cirurgia revelou que a ambivalência psíquica foi melhor suportada por essa mãe, trazendo momentos de confiança nas possibilidades de vida e de crédito na intervenção médica.

\section{d) A tomada de decisão}

Na decisão sobre a cirurgia, a mãe do caso 1 não referiu a ponderação de riscos, 0 surgimento de dúvidas ou questionamentos sobre os benefícios do procedimento, nem a exposição de seus medos aos outros (equipe, familiares ou colegas). Tampouco cogitou outras possibilidades e alternativas de cuidado. A não realização da cirurgia não podia sequer ser pensada, havendo uma disposição enfática em fazer a cirurgia e aderir imediatamente à indicação médica. Decidir significou "ter de fazer" a cirurgia. Esta foi associada à maior chance de viver, como se fosse isenta de riscos, e não fazê-la, à menor chance de viver. A convicção de decidir pela cirurgia como uma decisão pela vida revela que, nesse caso, houve pouco espaço psíquico para a apreciação dos vários aspectos (risco e benefício, vida e morte) presentes em qualquer decisão. Como o relato dessa mãe em muitos momentos expressava o oposto daquilo que se constatava de suas atitudes e ações, supôsse que a decisão inquestionável pela cirurgia poderia ser entendida como expressão do mecanismo psíquico de formação reativa (Freud, 1926/1996). Na formação reativa, um conflito inconsciente devido à ambivalência de querer e não querer a cirurgia dá origem à ênfase em uma única manifestação emocional - favorável à cirurgia - de forma a suprimir da consciência as tendências inconscientes opostas (de temer os riscos, de recusar ou questionar a cirurgia). Por trazerem conflitos à consciência, essas tendências são encobertas, resultando em uma manifestação tão ostentada e pronunciada da tendência contrária, a de aceitar, que desvia a atenção do lado conflituoso da ambivalência, como se não existisse. Concluiu-se que atitudes de recusa da cirurgia foram manifestadas indiretamente no caso 1 apesar das tentativas de afastá-las.

No caso 2, decidir implicou confrontar-se com o conflito diante do procedimento 
médico: autorizar algo que era para o bem da saúde física, mas que comportava riscos. Esse conflito pôde ser refletido pela mãe e a decisão ponderada. As atitudes observadas no processo decisório foram de recusar a intervenção, abandonar o tratamento e voltar para casa, como uma forma de fazer o bem para a filha e para ela: para a filha não sofrer tanto e ela não perder a filha. O medo de perder a filha na cirurgia era acirrado pelo falecimento de outras crianças, que lhe atestava que o tratamento podia ser falível. A recusa da cirurgia aparece como tendência momentânea devido a uma soma de circunstâncias adversas e significou uma proteção contra a perda. Observouse que houve reflexão tanto na atitude de recusa da cirurgia quanto na aceitação posterior, pois, apesar de ter cogitado algumas vezes tirar a filha do hospital, a mãe não concretizou essa atitude e pôde ponderála, sobretudo, a partir da interlocução com outras pessoas. A presença de "um outro" é importante para ajudar aquele que passa pela doença no relacionamento com esta que é uma experiência extremamente solitária (Knobloch, 2002).

Concluiu-se que, no caso 2, a decisão pela cirurgia derivou de uma aceitação fruto da reflexão: sobre as próprias ambivalências, a experiência de outras mães, as opiniões dos médicos e as consequências do recusar. As atitudes de recusa da realização da cirurgia contribuíram para decisões mais autônomas, pois permitiram a reflexão sobre as indicações médicas e as próprias atitudes antes da consolidação da decisão e do agir.

\section{d.1.) $\mathrm{O}$ futuro}

A preocupação com o futuro foi um ponto marcante no caso 1 e se referiu ao medo que a filha futuramente não aceitasse alguma intervenção médica. A mãe associou o não querer fazer a cirurgia a uma desistência do tratamento, mostrando uma perspectiva parcial de que recusar a cirurgia equivaleria a abandonar qualquer forma de tratamento médico e cuidado, ou ainda, equivaleria a desistir da vida. O medo que a autonomia da filha a conduzisse a um não aceitar a cirurgia foi analisado como expressão indireta de atitudes de recusa da mãe, depositadas no poder de decisão da filha na maioridade.

No caso 2, não houve alusões ao futuro como uma preocupação.

\section{e) Relação com o médico e a medicina}

No caso 1, as decisões tiveram um caráter pouco refletido e pouco autônomo. A rápida adesão às indicações médicas apontou para uma relação médico-paciente/cuidador de viés paternalista, em que o paciente/cuidador se mantém em uma posição de entrega e sujeição ao saber da medicina e, mesmo tendo questionamentos desse saber, fica receoso em expô-los. Para Knobloch (2002), a doença pode trazer uma alienação no sentido da desresponsabilização pelo próprio corpo e destino. Porém, a mãe do caso 1 mostrou como foi adquirindo, ao longo do tempo, um saber pela experiência, o qual pode favorecer uma relação mais equilibrada à medida que confere também aos pais, e não apenas ao médico, um lugar de saber sobre a doença e de responsabilidade sobre os destinos possíveis.

A mãe do caso 2 também fez referência ao conhecimento adquirido pela experiência com a doença, no sentido de ajudar a pensar, a ajuizar, inclusive a argumentar com os médicos sobre os tratamentos propostos. Foi possível alguma autonomia em relação às determinações médicas, pois essa mãe não inibiu suas inclinações e pensamentos de recusá-las, assim como considerou as opiniões externas divergentes das suas.

Knobloch (2002) comenta que algo de inexprimível atravessaria a relação médico- 
paciente: é frequente as palavras do paciente sumirem diante das palavras do médico, sendo que essa perda de palavras decorrente do sofrimento atinge igualmente o médico. Também Brun (1996) fala da incomunicabilidade na relação com o médico e de momentos de "surdez" da mãe diante das palavras do médico, decorrentes de um trabalho de negação que produz um discurso cheio de defesas para evitar tocar as próprias angústias de morte. Mas, apesar de não ser fácil falar da doença grave nem para o paciente nem para o médico, observou-se nos dois casos estudados momentos em que a "fala da medicina" prevaleceu e constituiu uma relação em que o paciente tende a ficar submetido à posição do médico.

\section{f) Relação com a filha}

No caso 1, analisou-se como a afirmação da mãe, de que mesmo que a filha não queira a cirurgia ela e o marido é que decidem, revela uma concepção de criança não participante das decisões, cuja voz e vontade não são levadas em conta. A criança é duplamente relegada a um lugar passivo que reproduz uma concepção paternalista das relações: como filha diante das determinações dos pais e como paciente diante das determinações médicas.

No caso 2, observou-se como a ameaça de separação pela doença foi compensada pelo vínculo estreito, pelo apego entre mãe e filha e a dificuldade de separação que a mãe relatou. Esse vínculo afetivo estreito foi entendido a partir da ideia de dupla cardíaca (Reze, 2006). Ao deixar mãe e filho em um suspense do que poderá acontecer, a cardiopatia faz com que ambos fiquem bastante apegados, como uma forma de compensar a vulnerabilidade de rompimento do vínculo devido ao risco de vida. A dupla cardíaca traria, então, um fortalecimento psíquico por meio do estreitamento do vínculo mãe-filho, da dedicação integral e da imersão da mãe na situação de doença (como se ela estivesse vivendo a doença em primeira pessoa). Se estabeleceria uma relação fusional transitória, porém não patológica, já que a formação da dupla seria uma estratégia de proteção psíquica para suportar as intensidades das angústias e seus efeitos traumáticos.

\section{Considerações sobre o campo da pesquisa}

A ACTC é uma casa de apoio que presta assistência a crianças/adolescentes cardiopatas e seus acompanhantes. Uma de suas influências na experiência das mães é que, em geral, se constitui como um contexto de "tratamento fora do domicílio de origem". Isso significa que os hóspedes da casa de apoio não vão embora para casa ao final do dia, não retornam às suas famílias e ao próprio contexto de pertencimento. Por ser frequente que apenas a mãe acompanhe o paciente, como ocorreu nos dois casos estudados, o tratamento fora do domicílio de origem faz com que ela esteja sozinha em circunstâncias pouco familiares. Estar desenraizada de todos os seus pontos de apoio pode angustiála e fazê-la dar-se conta do alto custo de acompanhar o tratamento do filho (Bousso, 2006). O tratamento fora do domicílio de origem faz recair sobre a mãe muitas atribuições, desde o dedicar-se integralmente aos cuidados do filho doente naquele período, não podendo voltar para casa para recarregar suas forças, até a necessidade de decisões imediatas sobre procedimentos médicos. Ainda que contem com o apoio familiar à distância, muitas situações são vividas pela mãe de forma solitária: é difícil compartilhar com quem não está presente os detalhes do andamento do tratamento, a conversa com os médicos, aquilo que se escuta nos corredores, as esperas, as expectativas, as melhoras na saúde do filho, as pioras. Também não é fácil para quem fica em casa, como o marido 
e os outros filhos que, muitas vezes, não têm a dimensão do que está se passando longe deles. Portanto, nesse contexto, a participação da família nas decisões sobre o tratamento pode ficar dificultada.

Outra influência desse contexto é o compartilhamento de experiências entre as mães na casa de apoio. Por viverem uma situação comum de doença de um filho, elas inevitavelmente compartilham sofrimentos, informações e expectativas, criando-se um tipo de compreensão empática entre elas, um apoio mútuo que traz consolo, fortalecimento e confiança. A convivência e o compartilhar de experiências pode ser algo benéfico e encorajador. Famílias que passam por situações parecidas, sobretudo no ambiente hospitalar, tendem a desenvolver interações significativas entre si, sendo que o testemunho da experiência alheia pode ajudar na compreensão e na reflexão sobre a própria experiência (Bousso \& Angelo, 2001). A busca por informações sobre situações semelhantes, com investigação das etapas futuras, pode auxiliar o processo de decisão sobre uma cirurgia (Bousso, 2006; Higgins, 2001). Contudo, se por um lado esse contato é interessante por servir como preparação, por outro lado pode introduzir ou antecipar questões que não serão necessariamente vividas por todos. Traz uma espécie de contágio de medos e angústias pelo testemunhar casos de desfecho negativo ou pelas perspectivas e informações extraoficiais que são transmitidas entre as mães. Não poder retornar ao ambiente familiar ao final de um dia de tratamento, o que amenizaria o foco exclusivo na doença e inseriria outras opiniões e estímulos na vida das mães, contribui ainda mais para essa impregnação.

Portanto, se ter um filho doente crônico já é suficiente para instalar uma situação de crise e de vulnerabilidade emocional, acrescentese a isso as influências desse contexto: mães sozinhas (eventualmente acompanhadas de algum familiar) com os filhos em uma cidade que não a própria, cercada por desconhecidos ou pessoas pouco íntimas, dedicando-se exclusivamente aos cuidados da criança e tendo de tomar decisões, muitas vezes emergenciais. Supôs-se que uma mãe nessas circunstâncias não teria as mesmas condições para assimilar, avaliar e decidir sobre ações para seu filho doente, em comparação a uma mãe que esteja em seu ambiente conhecido e amparada por familiares, os quais, além de dividir os cuidados da criança doente, ajudariam também na interlocução com os médicos. Destacou-se, assim, a importância de considerar que, ainda que temporária, a permanência nesse contexto de tratamento traz experiências de ruptura, cujas implicações nas atitudes maternas em relação aos processos decisórios não podem ser ignoradas.

\section{Conclusão}

Estudar como as mães decidem sobre a cirurgia cardíaca para o filho implicou considerar o contexto em que se constituem as atitudes maternas: de diagnóstico de uma doença grave do filho com prognóstico desfavorável, de indicação de uma cirurgia não definitiva e de tratamento permanente e realizado fora do domicílio de origem.

Constatou-se que os primeiros contatos com o diagnóstico, exames e a primeira cirurgia são os mais marcantes e difíceis, o que requer maior atenção da equipe de saúde nesses momentos iniciais. A reação materna ao diagnóstico tem ressonâncias significativas na sua reação à indicação cirúrgica e na tomada de decisão. Nos processos informativos sobre o quadro clínico da criança, as intervenções e prognósticos, deve-se considerar o tempo subjetivo da mãe de compreensão das informações, para que ao conteúdo já difícil de ser assimilado emocionalmente não se some uma comunicação abrupta, 
fragmentada ou excessivamente técnica. Também é importante o preparo do paciente e do acompanhante para cada etapa do tratamento, para que não sejam vividas de forma inesperada.

Observou-se que atitudes de recusa à cirurgia paliativa estão presentes na decisão, embora nem sempre explícitas. As atitudes de aceitação imediata da cirurgia não significaram uma aceitação isenta de atitudes de recusa; assim como aventar a recusa não significou que a cirurgia não tenha sido, depois, aceita. Concluiu-se que uma aceitação, de fato, implicaria o reconhecimento desses movimentos, assim como uma decisão plena e maturada requereria a consideração de ambas as tendências - de aceitação e de recusa do procedimento.

É tênue o limiar que distingue se a recusa da realização da cirurgia no filho seria uma reação impensada para se proteger das angústias decorrentes da ameaça de perda e dos riscos anunciados, ou se seria uma atitude refletida fruto de uma ponderação sobre o estado de saúde da criança e a relação risco-benefício da intervenção. Dos resultados obtidos, discutiu-se como algumas atitudes maternas de recusa poderiam ser entendidas como recusa-reflexão: a qual derivaria da abertura de um espaço psíquico de pensamento que daria condições à mãe de perceber, suportar e processar as muitas variáveis implicadas na situação. O pensar seria um recurso do psiquismo para colocar em análise e em relação os dados penosos da realidade, pois, ao criar um intervalo entre as notícias e vivências que afloram a angústia e as ações necessárias, permite-se a avaliação das recomendações médicas ao invés da subordinação irrefletida a estas ou da sua evitação defensiva.

Dessa perspectiva, a recusa materna de algo que poderia evitar o agravamento da doença do filho não significaria uma resignação indiferente frente ao destino, tampouco loucura, frieza, desamor ou desinvestimento afetivo da mãe. Seria uma reação possível frente aos riscos que existem tanto com a cirurgia quanto sem, indicando uma condição psíquica da mãe de perceber e refletir que não há só uma forma - por meio da cirurgia de enfrentar naquele momento a doença do filho. Cada caso requer uma análise singular das variáveis em jogo nas decisões, não se podendo ignorar o papel da crença religiosa dos pais, as noções familiares de cuidado e os tipos de cuidado que a mãe cogita. A possibilidade de pensar seria um recurso psíquico que proporcionaria a ponderação dessas variáveis, ajudando a mãe a entrever outras destinações possíveis, além da cirurgia, para a situação naquele momento. A recusa da cirurgia nem sempre significa a recusa de outras formas de tratamento ou cuidado; tampouco a recusa inicial quando ocorre a indicação da cirurgia significa que será definitiva. Cabe à prática psicológica abordar as atitudes de recusa como uma experiência materna possível e não descabida, que, ao expor uma hesitação, também revela os conflitos, dilemas e sofrimentos inerentes à decisão.

Como conclusão, propõe-se entender a decisão como um processo e um momento oportuno de reflexão para a mãe. Indicase, assim, o suporte psicológico no processo decisório da cirurgia paliativa para proporcionar, a partir da comunicação das informações médicas, um espaço em que esse processo possa ser refletido. Devido às reações que afloram pelo impacto emocional, a assimilação psíquica e a compreensão das informações pelos pacientes/cuidadores pode ficar prejudicada; além disso, a interpretação e o sentido que cada sujeito construirá depende de seu referencial cultural, desejos e expectativas. O suporte psicológico, ao legitimar as ambivalências psíquicas, as dúvidas, as consequências - inclusive jurídicas - pode favorecer a reflexão e 
a elaboração psíquica, valorizando a experiência subjetiva dos pais/cuidadores frente às indicações médicas. Assim, além da dimensão técnica, a dimensão subjetiva das decisões é valorizada, de modo que se tome uma decisão ponderada, consequente e com a qual a mãe, o pai, a criança, a família poderão conviver.
Devido às limitações dos propósitos e do alcance deste estudo, reconhece-se a relevância de em estudos futuros serem abordadas as experiências dos outros envolvidos no processo decisório, como o médico, o pai e, sobretudo, a criança cardíaca. 


\section{Bárbara Reze}

Mestre em Psicologia pelo Instituto de Psicologia da Universidade de São Paulo, São Paulo - SP - Brasil.

E-mail: barbara.reze@gmail.com

Endereço para envio de correspondência:

Rua Teodoro Sampaio, 744, cj. 42. CEP: 05406-000. São Paulo, SP.

Recebido 26/01/2012, Aprovado 12/12/2013.

\section{Referências}

Associação de assistência à criança cardíaca e à transplantada do coração (2010). Recuperado de http://www.actc.org.br.

Bousso, R. S.\& Angelo, M. (jun. 2001). Buscando preservar a integridade da unidade familiar: a família vivendo a experiência de ter um filho na UTI. Revista da Escola de Enfermagem da USP, 35(2), 172-179. doi: http://dx.doi. org/10.1590/S0080-62342001000200012

Bousso, R. S. (jun. 2006). A experiência da família durante a cirurgia cardíaca do filho. Nursing (São Paulo), 97(8), 860-865.

Brun, D. (1996). A criança dada por morta: riscos psíquicos da cura. São Paulo: Casa do Psicólogo.

Cohen, C.\& Marcolino, J.A.M. (2002). Relação Médico-Paciente: autonomia \& paternalismo. In C.Cohen, \& M. Segre, (Orgs), Bioética. (pp. 83-94). São Paulo: Edusp.

Culver, C.M. (2002). Relação Médico-Paciente: competência do paciente. In C. Cohen, \& M. Segre, (Orgs), Bioética (pp. 95-105). São Paulo: Edusp.

Freud, S. (1996). Formulação sobre os dois princípios do funcionamento mental. In S. Freud, Edição standard brasileira das obras psicológicas completas de Sigmund Freud (Vol. 12, pp. 231-244). Rio de Janeiro: Imago. (Trabalho original publicado em 1911).

Freud, S. (1996a). Os instintos e suas vicissitudes. In S. Freud, Edição standard brasileira das obras psicológicas completas de Sigmund Freud (Vol. 14, pp.115-144). Rio de Janeiro: Imago. (Trabalho original publicado em 1915).

Freud, S. (1996b). Reflexões para os tempos de guerra e morte. . In S. Freud, Edição standard brasileira das obras psicológicas completas de Sigmund Freud. (Vol. 14, pp.281-309). Rio de Janeiro: Imago. (Trabalho original publicado em 1915).

Freud, S. (1996). Além do princípio do prazer. In S. Freud, Edição standard brasileira das obras psicológicas completas de Sigmund Freud. (Vol. 18, pp.13-75). Rio de Janeiro: Imago. (Trabalho original publicado em 1920).

Freud, S. (1996). Inibições, sintomas e ansiedade. In S. Freud, Edição standard brasileira das obras psicológicas completas de Sigmund Freud (Vol. 20, pp.79-167). Rio de Janeiro: Imago. (Trabalho original publicado em 1926).

Giannotti-Hallage, A. (1983). Atitudes e reações emocionais de pais e pacientes com relação à cardiopatia congênita. Dissertação de Mestrado, Instituto de Psicologia, Universidade de São Paulo. São Paulo, SP
Giannotti-Hallage, A. (1988). Efeitos psicológicos das cardiopatias congênitas sobre o paciente e a família. Tese de Doutorado, Instituto de psicologia, Universidade de São Paulo. São Paulo, SP.

Higgins, S.S.\& Kayser-Jones, J. (jun. 1996). Factors influencing parent decision making about pediatric cardiac transplantation. Journal of Pediatric Nursing, 11(3), 152-160. doi: 10.1016/ S0882-5963(96)80048-0

Higgins, S.S. (2001). Parental role in decision making about pediatric cardiac transplantation: familial and ethical considerations. Journal of Pediatric Nursing, 16(5), 332-337. doi: 10.1053/jpdn.2001.27209

Hossne, W.S. (2002). Relação Médico-Paciente: competência do médico. In C. Cohen, \& M. Segre (Orgs), Bioética (pp. 106-118). São Paulo: Edusp.

Hottois, G.\& Parizeau, M.H. (1993). Dicionário da bioética. Lisboa, PT: Instituto Piaget.

Kipper, D.J., Clotet, J. \& Loch, J.A. (jan./mar. 2004). A autonomia na infância e na juventude. Scientia Medica 14(1), 3-11.

Knobloch, F. (1998). O tempo do traumático. São Paulo: EDUC.

Knobloch, F. (2002). Patoplastias do contemporâneo: clínica do corpo em sofrimento. Tese de Doutorado em Psicologia Clínica, Pontifícia Universidade Católica de São Paulo. São Paulo, SP.

Pinnock, R.\& Crosthwaite, J. (2005). When parents refuse consent to treatment for children and young persons. Journal of Paediatric Child Health,41, 369-373. doi: 10.1111/j.14401754.2005.00643.x

Reze, B. (2006). Cardiopatia infantil: implicações na relação entre mãe e filho. Psicologia Revista, 15(1),11-20.

Romano, B.W. (2001). Psicologia e Cardiologia: encontros possíveis. São Paulo: Casa do Psicólogo.

Turato, E. R. (2008). Tratado da metodologia da pesquisa clínicoqualitativa: construção teórico-epistemológica, discussão comparada e aplicação na área da saúde e humanas. Petrópolis, RJ: Vozes.

Vandvik, I.H.\& Forde, R. (2000). Ethical issues in parental decision making. An interview study of mothers of children with hypoplastic left heart syndrome. Acta Paediatr, 89, 1129-1133. doi: 10.1111/j.1651-2227.2000.tb03363.x 